\title{
Determinación del punto isoeléctrico de las proteínas presentes en cuatro fuentes foliares: yuca (Manihot esculenta Crantz) variedades verónica y tai, jatropha (Jatropha curcas L.) y gmelina (Gmelina arbórea)
}

\section{Determination of the isoelectric point of four leaf sources: cassava (Manihot esculenta Crantz) veronica and tai varieties, jatropha (Jatropha curcas L.) and gmelina (Gmelina arborea)}

\author{
Angélica M. Serpa Guerra, ${ }^{1,4}$, Gustavo Hincapié Llano², ${ }^{2}$, Catalina Álvarez López ${ }^{3,4}$ \\ ${ }^{1}$ Especialista en alimentación y nutrición, Ingeniera Agroindustrial, Joven Investigador de la Universidad Pontificia Bolivariana \\ ${ }^{2}$ Magíster en Ingeniería Ambiental, Químico, Universidad Pontificia Bolivariana, Medellín, Colombia \\ ${ }^{3}$ PhD. en Ingeniería, Ingeniera Agroindustrial, Universidad Pontificia Bolivariana, Medellín, Colombia, catalina.alvarezl@upb.edu.co \\ ${ }^{4}$ Grupo de Investigaciones Agroindustriales, Medellín, Colombia
}

Recibido 30/01/14, aceptado 3/03/2014

\section{RESUMEN}

La extracción de proteína a partir de residuos agroindustriales, surge como una alternativa de aprovechamiento y desarrollo de nuevos productos. Para esto, es fundamental conocer su punto isoeléctrico, $\mathrm{pH}$ en el cual la proteína presenta su mínima solubilidad y por tanto precipita. En el presente trabajo se determinó el pH isoeléctrico de las proteínas presentes en 4 fuentes foliares: yuca (Manihot esculenta Crantz) variedades verónica y tai, jatropha (Jatropha curcas L.) y gmelina (Gmelina arbórea). Para la obtención de las proteínas se realizó una extracción alcalina con $\mathrm{NaOH} 0,1 \mathrm{M}$; y una precipitación evaluando tres valores de $\mathrm{pH}(4,0-4,25-4,5)$ y 2 temperaturas (temperatura ambiente y $50{ }^{\circ} \mathrm{C}$ ). Todos los precipitados obtenidos a $50^{\circ} \mathrm{C}$ presentaron el mayor contenido de proteína. El pH isoeléctrico para la yuca variedad tai y para la jatropha fue 4,0 y 4,5 respectivamente, siendo el precipitado de jatropha el que mayor contenido de proteína presentó $(32,10 \%$ BS), seguido por la yuca variedad tai $(31,22 \%)$ y la yuca variedad verónica $(27,59 \%)$. Esta ultima fuente foliar no presentó diferencia estadísticamente significativa entre 2 de los valores de $\mathrm{pH}$ evaluados $(4,0$ y 4,5), situación similar a lo sucedido con los precipitados de gmelina quienes no presentaron diferencia estadísticamente significativa entre los tres valores de $\mathrm{pH}$ trabajados. Finalmente, la jatropha obtuvo el mayor rendimiento de extracción $\left(31,24 \%\right.$ ) y el menor de precipitación a $50^{\circ} \mathrm{C}$.

Palabras clave: Proteína foliar, Precipitación, Extracción, Punto isoeléctrico.

\begin{abstract}
Protein extraction from agro-industrial waste is an alternative for the use and development of new products. For this reason, it is very important to know its isoelectric $\mathrm{pH}$, where protein has a minimum solubility and thus precipitates. In this investigation, the isoelectric $\mathrm{pH}$ of proteins from 4 leaves: from cassava (Manihot esculenta Crantz) veronica and tai varieties, jatropha (Jatropha curcas L.) and gmelina (Gmelina arborea) was determined. Samples were treated with an alkaline solution $(0.1 \mathrm{M} \mathrm{NaOH})$, and the protein extracted was precipitated using three $\mathrm{pH}$ values (4.0 to 4.25 - 4.5) and two different temperatures (room temperature to $50{ }^{\circ} \mathrm{C}$ ). Cassava variety veronica and gmelina precipitates did not show statistically significant difference between the three-pH values. However, the isoelectric $\mathrm{pH}$ for cassava and jatropha tai was observed at 4.0 and 4.5 respectively. Jatropha had the highest extraction yield $(31.24 \%)$ and the lowest precipitation at $50{ }^{\circ} \mathrm{C}$.
\end{abstract}

Keywords: Leaf protein, Precipitation, Extraction, Isoelectric $\mathrm{pH}$. 


\section{INTRODUCCIÓN}

Colombia se caracteriza por ser un país cuyo territorio permite la explotación agroindustrial de diversos cultivos de tubérculos incluyendo la papa, el ñame y la yuca, cultivos para la obtención de energía como la caña y la jatropha, al igual que la siembra controlada para la explotación forestal. Todas estas son actividades que conllevan a la generación de altas cantidades de residuos y por tanto, a la búsqueda de alternativas para su posterior aprovechamiento.

La yuca (Manihot esculenta Crantz) es una planta perteneciente a la familia Euphorbiaceae, originaria de América del Sur [1], cuyo cultivo representa el cuarto producto más importante en la alimentación mundial, después del arroz, el trigo y el maíz [2]. En Colombia, al igual que en otros lugares del mundo, este cultivo es manejado por pequeños agricultores y gracias a su buen comportamiento en condiciones difíciles de clima y suelo, contribuye a la seguridad alimentaria en poblaciones de bajos recursos económicos [3]. La principal zona de producción de yuca es la región Caribe, donde se concentra el $42 \%$ de la producción nacional [4], la cual para el año 2012 fue de 2'279.358 ton, cultivadas en aproximadamente 211.714 ha [5].

El cultivo de yuca se basa en la obtención de la raíz comestible, sin embargo, las hojas de este cultivo han ganado importancia debido a la cantidad de proteína presente en las mismas, la cual corresponde al $24,62 \%$ en base seca [6]. El número de hojas de yuca producidas, su longevidad y tasa de producción son características varietales que cambian según las condiciones ambientales, sin embargo al realizar un aprovechamiento eficiente del cultivo, se puede obtener aproximadamente entre 1 y 3 toneladas de follaje por hectárea [7]. En la actualidad, la proteína de las hojas de yuca no es utilizada para alimentación humana debido a su contenido de ácido cianhídrico [6], gracias a que éste se une a la citocromo c oxidasa, impidiendo la utilización del oxígeno a nivel celular [8].

La Jatropha (jatropha curcas L.) es una planta perenne de crecimiento rápido [9] proveniente de Centro y Sur América, utilizada como controlador de erosión y árbol de sombra [10]. En los últimos años ha adquirido importancia comercial en Colombia por su alto potencial para la obtención de biocombustible [11], gracias a su alta producción y calidad del aceite [12]. Sin embargo, por ser un cultivo relativamente nuevo y en crecimiento, no existe una base sólida de información, y en la actualidad solo se conocen reportes sobre la evaluación del cultivo de Jatropha en Puerto CarreñoVichada [13] y en Sopetran Antioquía, donde se encuentra la empresa Biocombustibles S.A. y él centro de investigación Colbio [14]. Otras zonas potenciales para el cultivo de Jatropha curcas en Colombia son Urabá, sur de Tolima, Alta Guajira y Desierto de la Tatacoa [13].
En el cultivo de la Jatropha curcas, al igual que en el de la yuca, pese a que las hojas poseen un alto contenido de proteína $(18,8 \%)$ [15], éstas no son utilizadas para alimentación humana ni animal debido a su contenido de cianuro [10]. Situación similar ocurre con la semilla, el aceite y los subproductos de la extracción del aceite (torta), los cuales poseen componentes tóxicos conocidos como ésteres de forbol [16], limitando su uso a procesos no alimentarios.

En cuanto a la producción forestal, Colombia cuenta con aproximadamente 17 millones de hectáreas aptas para su explotación, distribuidas en varios pisos altitudinales, lo que permite la plantación de diversas especies. Esta característica ha permitido desarrollar un alto potencial para la reforestación comercial a partir de la cual se produce un promedio anual de $561.571 \mathrm{~m}^{3}$ de madera aserrada [17]. Dentro de las especies cultivadas en Colombia se encuentra el árbol maderable gmelina arbórea, perteneciente a la familia Verbenaceae [18], la cual es utilizada para programas de plantaciones industriales con fines de desarrollo económico y social [19]. En el territorio Nacional existen aproximadamente 14.000 hectáreas sembradas de gmelina concentradas principalmente en la Costa Atlántica y 450 hectáreas en el departamento del Tolima, especialmente en los suelos de los valles del rio Magdalena $[19,20]$. Se ha reportado que las hojas de la Gmelina arbórea presentan valores de proteína de hasta un 15,92\% [21], sin embargo, en la actualidad su uso se limita al forraje para el ganado y alimento para el gusano de seda [22].

Debido al contenido proteico que se reporta para las hojas provenientes de los cultivos de yuca, jatropha y gmelina, las cuales se pueden considerar residuos de actividades de explotación agrícola con una alta producción en el país, se plantea la necesidad de estandarizar procesos de extracción de proteína como una opción de aprovechamiento de estos residuos para su posterior uso en el desarrollo de adhesivos naturales [23] o alimentación animal [24].

Las proteínas presentes en fuentes foliares son insolubles en agua gracias a su naturaleza hidrofóbica y a las uniones disulfuro entre las moléculas proteicas [25], dificultando su extracción debido a las características metabólicas y estructurales de los tejidos, especialmente de la pared celular [26]. Para lograr su precipitación, las proteína deber ser liberadas de las células vegetales que las contiene [27], utilizando solventes selectivos con respecto al soluto [28]. Los solventes altamente alcalinos ayudan a romper los puentes de hidrógeno y a disociar el hidrógeno de los grupos sulfato carbólico, así el incremento de la carga superficial de las moléculas proteicas aumenta la solubilidad en agua [25], como muestran estudios previos, en los que se utilizó como solvente $\mathrm{NaOH}$ al $0.1 \mathrm{M}$, logrando extracciones entre el $55 \%$ y $90 \%$ de proteína de arroz $[29,30]$ y $56,4 \%$ de proteína de hojas de té [25], al igual que extracciones con $\mathrm{Ca}(\mathrm{OH})_{2}$ de proteína de pasto elefante [31]. 
En el presente trabajo se determinó el punto isoeléctrico de las proteínas provenientes de 4 fuentes foliares, necesario para lograr su precipitación y posterior separación. Se evaluó el porcentaje de proteína de las 4 fuentes foliares y de los precipitados obtenidos, además de su contenido de ceniza con el fin de caracterizar el extracto.

\section{MATERIALES Y MÉTODOS}

\subsection{Material foliar}

Se evaluaron 4 fuentes de material foliar provenientes de cultivos de melina (Gmelina arbórea), jatropha (Jatropha curcas $L$ ) y yuca (Manihot esculenta Crantz) variedades verónica y tai. Las muestras fueron suministradas por forestales para siempre S.A.S (Medellín), el Centro de Investigación Colombiana de Biocombustibles - Colbio S.A. (Sopetrán) y Almidones de Sucre S.A.S (Sucre) respectivamente. Las hojas se secaron en un horno de convección forzada a $45^{\circ} \mathrm{C}$ por 4 horas para lograr su deshidratación y conservación. El material seco se molió y se tamizó en una tamizadora eléctrica con temporizador marca SUELOS E ING Modelo PS-35, utilizando un tamiz ASTM malla 18. Las muestras fueron denominadas como se muestra en la Tabla 1.

Tabla 1. Denominación de las muestras

Table 1. Name of samples

\begin{tabular}{|l|c|c|c|}
\hline \multicolumn{1}{|c|}{ Muestra } & Identificación & Extracto & Precipitado \\
\hline Hojas de Yuca (tai) & HY-T & EY-T & PY-T \\
\hline Hojas de Yuca (verónica) & HY-V & EY-V & PY-V \\
\hline Hojas de Jatropha & HJ & EJ & PJ \\
\hline Hojas de Gmelina & HG & EG & PG \\
\hline
\end{tabular}

\subsection{Caracterización de las hojas deshidratadas}

El contenido de proteína se determinó por el método Kjeldhal en un equipo Velp scientifica, dotado de un digestor DKL, un aspirador de agua de recirculación JP y una unidad de destilación automática UDK-149. Las muestras secas se llevaron a digestión completa utilizando una rampa de temperatura $\left(170{ }^{\circ} \mathrm{C}\right.$ por $15 \mathrm{~min}, 230^{\circ} \mathrm{C}$ por $15 \mathrm{~min}$, $320^{\circ} \mathrm{C}$ por $45 \mathrm{~min}$ y $420^{\circ} \mathrm{C}$ por $45 \mathrm{~min}$ ) para su posterior destilación y formación del borato de amonio, el cual luego fue titulado con ácido sulfúrico para obtener el valor de proteína en cada fuente foliar, utilizando como factor de conversión 6.24 (AOAC 955.04D). La humedad de las muestras deshidratadas se determinó por desecación en estufa a $105^{\circ} \mathrm{C}$ hasta peso constante (AOAC 934.01/05) utilizando un horno marca Binder modelo ED 23-UL. El contenido de cenizas se halló utilizando una mufla marca Terrigeno modelo D8 de acuerdo al método de calcinación (AOAC 942.05/05).

\subsection{Obtención de los extractos}

Las muestras secas se mezclaron con una solución de $\mathrm{NaOH}$ 0.1M, empleando una relación 1:15 w/v. La dispersión se agitó durante 5 minutos a $30^{\circ} \mathrm{C}$ y posteriormente se filtró para obtener las soluciones con los extractos proteicos, cuya denominación se muestra en la Tabla 1.

\subsection{Determinación del punto isoeléctrico}

La determinación del punto isoeléctrico se llevó a cabo de acuerdo al método descrito por Spell y Bressani [32] modificado [31]. Cada extracto obtenido se llevó a un $\mathrm{pH}$ de 4,0- 4,25 y 4,5 utilizando $\mathrm{HCl}$ 0,1 M, con el fin de abarcar el rango descrito en la bibliografía como puntos isoeléctricos de la proteína foliar [31]. Se evaluaron 2 temperaturas de precipitación: temperatura ambiente y $50^{\circ} \mathrm{C}$. Las muestras tratadas se llevaron a agitación constante durante 30 minutos y posteriormente fueron centrifugadas en una centrifuga HETTICH Zentrifuguen modelo D78532 por 5 minutos a 5000rpm. El sobrenadante se descartó y el precipitado se secó a $60^{\circ} \mathrm{C}$ por 24 horas, con el fin de alcanzar peso contante. El punto isoeléctrico se estableció en el valor de $\mathrm{pH}$ donde el precipitado presentara mayor contenido de proteína. El procedimiento se realizó por triplicado. El contenido de proteína, humedad y cenizas se determinó como se describió anteriormente.

Con el fin de determinar el rendimiento de la extracción y en base a este, el rendimiento de precipitación, se cuantificó el contenido de proteína remanente en la fuente foliar después del tratamiento como se describió previamente.

\subsection{Determinación de los rendimientos de extracción y precipitación de proteína.}

Para calcular el rendimiento de extracción, se determinó el contenido de proteína remanente en las hojas después de llevado a cabo el proceso de extracción en la solución de hidróxido de sodio a $50^{\circ} \mathrm{C}$, con el fin de obtener los gramos de proteína extraída, para finalmente, calcular el porcentaje de extracción de proteína con la ecuación 1.

\%Extracción de proteína $=\frac{g \text { proteina de proteína extraida }}{g \text { proteina despues de la extraccion }} \times 100$ Ec. 1

Para el rendimiento de precipitación de proteína, también fue necesario llevar el porcentaje de proteína en los precipitados, a gramos de proteína obtenidos, teniendo en cuenta la cantidad de precipitado obtenido en cada caso, para finalmente obtener el rendimiento de precipitación, con respecto a la proteína extraída, con la ecuación 2.

$\%$ Precipitación de proteína $=\frac{g \text { proteina precipitada }}{\text { g proteina extraida }} \times 100$ Ec. 2 


\subsection{Tratamiento estadístico}

Las variables respuesta fueron la cantidad de proteína obtenida en cada uno de los valores de $\mathrm{pH}$ y las dos temperaturas de precipitación evaluadas para cada una de las muestras. A los resultados se les realizó el análisis de varianza (one-way ANOVA), utilizando statgraphics 5.1, con el fin de determinar la diferencia estadísticamente significativa entre los valores obtenidos para cada variable respuesta.

\section{RESULTADOS Y DISCUSIÓN}

\subsection{Caracterización de las cuatro fuentes foliares}

El contenido de humedad, cenizas y de proteína de las 4 fuentes foliares se muestran en la Tabla 2. El mayor contenido de proteína lo presentaron las hojas de jatropha con $18,31 \%$, valor que se encuentra dentro del rango reportado para este material foliar (9,4 a 18,8\%) [15] y el cual es superior al de otras especies como la jatropha tanjorensis $(9,47 \%)$ [33]. En el caso de las hojas de yuca se evidenció una diferencia en el contenido de proteína de las dos variedades analizadas; para HY-V este fue de $15,92 \%$, mientras que HY-T mostró un porcentaje de $17,43 \%$, siendo ambos valores inferiores a los reportados por otros autores $(22,0-22,7 \%)[6,34]$. Por su parte, las hojas de gmelina presentaron el contenido más bajo de proteína $(6,68 \%)$ y el que más se alejó de lo reportado en la literatura $(15,92 \%)$ [21], sin embargo el valor obtenido se asemeja al de otras fuentes foliares de árboles como Moringa oleífera $(7,2 \%)$ [35] y maderables como Cedrus libani $(9,4 \%)$ y Pinus halepensis $(10,5 \%)$ [36].

El contenido de cenizas de las 4 muestras se encuentra en un rango de 7,68-14,92\%, lo que indica un alto contenido de este componente en todas las muestras. La fracción correspondiente a las cenizas obtenidas para la muestra de yuca tai $(10,5 \%)$ fue similar al reportado en la bibliografía de $11,80 \%$ [6], mientras que el contenido en la variedad verónica fue menor $(8,29 \%)$, caso similar al resultado obtenido para la gmelina, cuyo valor $(7,68 \%)$ fue menor al reportado de 9,77\% [21]. Finalmente, el valor obtenido para las hojas de jatropha $(14,92 \%)$ fue mayor al reportado en la bibliografía de 12,00\% [37]. Las diferencias encontradas entre el contenido de cenizas de las muestras analizadas y el valor reportado por otros investigadores, se debe, al igual que en el caso de la proteína, a que la concentración de cenizas en la fuente foliar depende de diversos factores, incluyendo el tipo de suelo [38], los métodos de fertilización y la especie [39].
Tabla 2. Características químicas de las 4 fuentes foliares Table 2. Chemical characteristics of the 4 samples

\begin{tabular}{|l|c|c|c|}
\hline Muestra & Proteína BS (\%) & Humedad (\%) & Cenizas BS (\%) \\
\hline HY-T & $17,43 \pm 0,10$ & $6,78 \pm 0,30$ & $10,50 \pm 0,10$ \\
\hline HY-V & $15,91 \pm 0,09$ & $5,30 \pm 0,11$ & $8,29 \pm 0,36$ \\
\hline HJ & $18,31 \pm 0,01$ & $5,85 \pm 0,40$ & $14,92 \pm 0,25$ \\
\hline HG & $6,67 \pm 0,01$ & $4,71 \pm 0,01$ & $7,68 \pm 0,69$ \\
\hline
\end{tabular}

Los altos contenidos de cenizas se explican debido a la presencia de minerales como hierro, zinc, potasio y fósforo, entre otros, en la lamina foliar [6], además, se sabe que en las plantas el contenido de minerales varía entre 1 y $12 \%$, mostrando los forrajes un mayor contenido que las semillas o granos [39], de allí que el contenido de ceniza obtenido para las hojas de jatropha $(14,92 \%)$, fuese mayor al reportado para sus semilla $(3,62-4,21 \%)$ [40]. Las diferencias que se presentan entre los valores obtenidos y los reportados en la literatura, se deben, entre otras razones, a que el contenido de proteína depende de diversos factores, incluyendo la variedad, etapa de crecimiento, condiciones climáticas [41], tratamientos silviculturales [42] y concentración de nitrógeno en el suelo. En el último caso, niveles bajos de este elemento conllevan a una disminución de la síntesis de proteínas en las plantas [43].

Según Lyons, el material foliar de los arbustos como la jatropha y la yuca presentan un mayor contenido de proteína en sus hojas que las gramíneas, gracias a que poseen mayor contenido celular [44], de allí que los contenidos de proteína encontrados para éstas 2 fuentes foliares fuesen mayores que las reportadas para gramíneas como el maíz $(6,67$ y $14,32 \%)$ [45] y la caña de azúcar (5 y 8,3\%) [46]. La humedad hace referencia a los valores alcanzados después del secado por convección forzada, necesario para lograr la conservación de las hojas evitando su deterioro, en este caso las fuentes foliares deshidratadas alcanzaron humedades entre $4,71 \%$ y $6,78 \%$, dicha variación se presenta debido a que cada material, presenta un valor de humedad de equilibrio especifica.

\subsection{Determinación del punto isoeléctrico}

En las Figuras 1 y 2 se observa el contenido de proteína de los 4 precipitados obtenidos después de realizar la precipitación a temperatura ambiente y a $50^{\circ} \mathrm{C}$ respectivamente. $\mathrm{El} \mathrm{pH}$ isoeléctrico se determinó de acuerdo al valor en el cual el precipitado presentó mayor contenido de proteína, y se refiere al $\mathrm{pH}$ donde la proteína no tiene carga eléctrica y es incapaz de desplazarse en un campo eléctrico, por lo que no existe repulsión electrostática entre las moléculas de proteína vecinas y tienden a precipitar [47]. 
Al comparar las figuras anteriores, se observa que en general los precipitados obtenidos a $50^{\circ} \mathrm{C}$ presentaron mayor contenido de proteína que los alcanzados a temperatura ambiente, lo que corrobora los resultados obtenidos por Urribarrí C., Ferrer O., \& Colina [31], quienes mostraron que el incremento de la temperatura disminuye la solubilidad de la proteína en la solución, y por tanto se favorece una mayor precipitación de la misma, gracias a que la temperatura rige diversos factores de la solubilidad de las proteínas [48]. Los resultados muestran que bajo estas condiciones, la variación más marcada se presentó para la Jatropha, donde un incremento de la temperatura de precipitación generó $10 \%$ más de proteína precipitada, mientras que la Gmelina presentó el menor cambio, entre 2 y $2.1 \%$.

Por otra parte, al observar ambas gráficas, se reconoce que al realizar la precipitación a temperatura ambiente, los resultados en los 3 valores de $\mathrm{pH}$ no presentaron gran variación, contrario a lo sucedido con la precipitación a $50^{\circ} \mathrm{C}$, donde se observa una diferenciación entre los valores obtenidos para cada uno de los pHs. Específicamente, para las proteínas obtenidas a partir de las dos variedades de yuca y de la jatropha, un incremento en la temperatura se relacionó con un aumento en el contenido de proteína obtenida a $\mathrm{pH} 4,0$ y $\mathrm{pH} 4,5$.

La importancia de la temperatura en el proceso de precipitación, también se observa al analizar los resultados del análisis de varianza que se muestra en la Tabla 3. En general, los valores de proteína obtenidos durante la precipitación a temperatura ambiente para cada fuente foliar, no presentaron diferencia estadísticamente significativa, contrario a lo que sucedió al realizar la precipitación a $50^{\circ} \mathrm{C}$, donde los valores obtenidos para la jatropha a $\mathrm{pH} 4,0 \mathrm{y} \mathrm{pH}$ 4,25, para la yuca variedad verónica a $\mathrm{pH} 4,0$ y 4,5 y los obtenidos para la gmelina a los 3 valores de $\mathrm{pH}$ evaluados, no presentaron diferencias estadísticamente significativas.

Figura 1. Proteína presente en los precipitados obtenidos a temperatura ambiente

Figure 1. Precipitated protein of the extraction and precipitation at room temperature

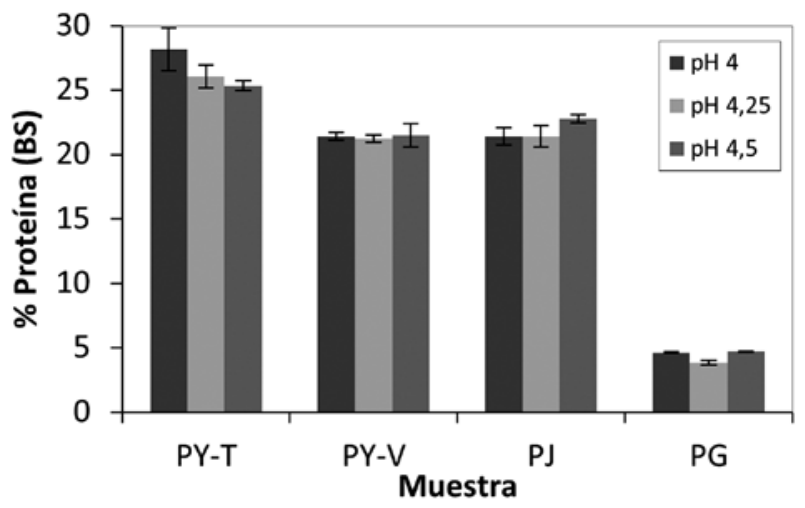

Figura 2. Proteína presente en los precipitados obtenidos a $50^{\circ} \mathrm{C}$ Figure 2. Precipitates protein content obtained at $50^{\circ} \mathrm{C}$

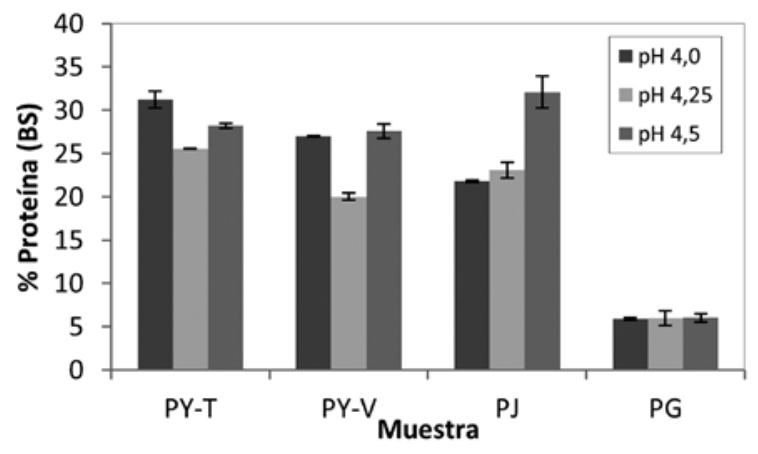

La planta que presentó el precipitado con mayor contenido de proteína fue la jatropha $(32,10 \%)$, a un $\mathrm{pH}$ isoeléctrico de 4,5 y una temperatura de precipitación de $50^{\circ} \mathrm{C}$. Por otro lado para la yuca variedad tai, el $\mathrm{pH}$ isoeléctrico fue 4, obteniéndose también mayor porcentaje de proteína al realizar la precipitación a $50^{\circ} \mathrm{C}$. Estos valores son semejantes a los reportados para la proteína precipitada de otras fuentes foliares como maíz [45], chaya [32], plantas acuáticas [49] y pasto elefante [31]. Para de gmelina, al igual que para la yuca variedad verónica no se pudo establecer el $\mathrm{pH}$ isoeléctrico, ya que los resultados obtenidos para la gmelina en los 3 valores de $\mathrm{pH}$ y para la yuca verónica en los pHs 4,0 y 3,5, no presentaron diferencia estadísticamente significativa.

Las medias con la misma letra dentro de cada fila no son diferentes significativamente según la prueba de Duncan (Valor $\mathrm{P} \leq 0.05$ )

Finalmente, el precipitado con menor contenido de proteína fue el obtenido a partir de las hojas de gmelina, resultado que se esperaba, debido a los contenidos de proteína iniciales en las hojas.

La composición química de cada proteína es característica y presenta un número diferente de grupos ionizables que se neutralizan a diferente $\mathrm{pH}$ [50], de allí que no exista un valor único de $\mathrm{pH}$ como punto isoeléctrico, ya que éste depende de la naturaleza de la proteína, es decir, de los aminoácidos y péptidos que la constituyen, al igual que de las interacciones que existan entre estas moléculas y el medio.

\section{Contenido de humedad y cenizas en los precipitados}

El contenido de humedad y de cenizas de los cuatro precipitados para los 3 valores de $\mathrm{pH}$ evaluados y las 2 temperaturas trabajadas se muestran en las Tablas 4 y 5, siendo el precipitado de gmelina obtenido a $\mathrm{pH} 4,25$ y a $50^{\circ} \mathrm{C}$ el que mayor contenido de ceniza presentó, sin embargo los resultados obtenidos para cada fuente foliar en su respec- 
Tabla 3. Resultados del análisis de varianza a temperatura ambiente y $50^{\circ} \mathrm{C}$

Table 3. Variance analysis results at room temperature and at $50^{\circ} \mathrm{C}$

\begin{tabular}{|c|c|c|c|c|c|c|c|c|c|c|c|c|}
\hline \multirow{2}{*}{$\begin{array}{l}\text { Muestra } \\
\text { PY-T }\end{array}$} & \multicolumn{6}{|c|}{ \% Proteína - Precipitación a T. Amb. } & \multicolumn{6}{|c|}{$\%$ Proteína - Precipitación a $50^{\circ} \mathrm{C}$} \\
\hline & $28,18 \pm 1.66$ & a & $26,05 \pm 0.90$ & $a, b$ & $25,32 \pm 0,39$ & $\mathrm{~b}$ & $31,23 \pm 0,94$ & $\mathrm{~h}$ & $25,53 \pm 0,02$ & $\mathrm{i}$ & $28,20 \pm 1,25$ & $\mathrm{j}$ \\
\hline PY-V & $21,40 \pm 0,31$ & c & $21,25 \pm 0,28$ & $\mathrm{C}$ & $21,48 \pm 0,90$ & $\mathrm{c}$ & $26,99 \pm 0,08$ & $\mathrm{k}$ & $20,02 \pm 0,4$ & 1 & $27,59 \pm 0,68$ & $\mathrm{k}$ \\
\hline PJ & $21,40 \pm 0,65$ & $\mathrm{~d}$ & $21,41 \pm 0,80$ & $\mathrm{~d}$ & $22,78 \pm 0,33$ & $\mathrm{e}$ & $21,81 \pm 0,13$ & $\mathrm{~m}$ & $23,08 \pm 0,90$ & $\mathrm{~m}$ & $32,10 \pm 1,83$ & $\mathrm{n}$ \\
\hline
\end{tabular}

Tabla 4. Contenido de cenizas y humedad de los 4 precipitados obtenidos a temperatura ambiente Table 4. Chemical characteristics of the 4 precipitates obtained at room temperature

\begin{tabular}{|l|l|l|l|l|l|l|}
\hline \multirow{2}{*}{ Muestra } & \multicolumn{1}{|c|}{ Cenizas (\%) } & \multicolumn{1}{|c|}{ Humedad (\%) } & \multicolumn{1}{c|}{ Cenizas (\%) } & \multicolumn{1}{c|}{ Humedad (\%) } & \multicolumn{1}{c|}{ Cenizas (\%) } & \multicolumn{2}{c|}{ Humedad (\%) } \\
\cline { 2 - 8 } & \multicolumn{2}{|c|}{ pH 4,0 } & \multicolumn{2}{c|}{ pH $\mathbf{2 5}$} & \multicolumn{2}{c|}{ pH 4,5 } \\
\hline PY-T & $9,98 \pm 0,13$ & $11,58 \pm 0,08$ & $9,99 \pm 0,02$ & $8.99 \pm 0,15$ & $12,36 \pm 0,12$ & $11,41 \pm 0,14$ \\
\hline PY-V & $7,83 \pm 0,23$ & $7,27 \pm 0,18$ & $10,04 \pm 0,08$ & $8,41 \pm 0,79$ & $8,99 \pm 0,49$ & $4,86 \pm 0,29$ \\
\hline PJ & $8,91 \pm 0,54$ & $8,94 \pm 0,28$ & $8,71 \pm 0,38$ & $5,34 \pm 0,27$ & $10,64 \pm 0,03$ & $6,81 \pm 0,03$ \\
\hline PG & $12,38 \pm 0,11$ & $10,32 \pm 0,29$ & $12,78 \pm 0,09$ & $7,63 \pm 0,34$ & $13,76 \pm 0,27$ & $10,72 \pm 0,13$ \\
\hline
\end{tabular}

Tabla 5. Contenido de cenizas y humedad de los 4 precipitados obtenidos a $50^{\circ} \mathrm{C}$

Table 5. Ash and moisture content of the 4 precipitates obtained at $50^{\circ} \mathrm{C}$

\begin{tabular}{|l|c|c|c|c|c|c|}
\hline \multicolumn{1}{|c|}{ Muestra } & Cenizas (\%) & Humedad (\%) & Cenizas (\%) & Humedad (\%) & Cenizas (\%) & Humedad (\%) \\
\hline & \multicolumn{2}{|c|}{ pH 4,0 } & \multicolumn{2}{c|}{ pH 4,25 } & \multicolumn{2}{c|}{ pH 4,5 } \\
\hline PY-T & $7,48 \pm 0,03$ & $5,53 \pm 0,01$ & $10,71 \pm 0,28$ & $7,46 \pm 0,79$ & $3,24 \pm 0,01$ & $5,25 \pm 0,01$ \\
\hline PY-V & $7,32 \pm 0,02$ & $7,60 \pm 0,01$ & $8,57 \pm 0,05$ & $5,86 \pm 0,06$ & $7,40 \pm 0,06$ & $4,34 \pm 0,01$ \\
\hline PJ & $8,78 \pm 0,01$ & $5,86 \pm 0,05$ & $7,43 \pm 0,51$ & $7,75 \pm 0,20$ & $13,67 \pm 0,04$ & $5,50 \pm 0,10$ \\
\hline PG & $6,21 \pm 0,01$ & $6,78 \pm 0,02$ & $13,40 \pm 0,16$ & $11,48 \pm 0,02$ & $7,542 \pm 0,02$ & $5,68 \pm 0,01$ \\
\hline
\end{tabular}

tivo punto isoeléctrico, muestran que los porcentajes son muy altos, disminuyendo así la pureza de los extractos proteicos.

De manera general, el contenido de cenizas presente en los precipitados proteicos fue mayor al encontrado en las hojas, mientras que el contendido de humedad, fue menor.

La precipitación química de metales pesados, es una de las técnicas más utilizadas para la remoción de este tipo de elementos, que se logra, disminuyendo su solubilidad por medio de la adición de sustancias químicas [51], o modificando el pH de la solución [52]. Lo anterior, permitiría establecer, que gran parte de las cenizas obtenidas para cada muestra, están compuestas por metales pesados precipitados durante la obtención de las proteínas.

\subsection{Rendimiento de extracción y precipitación}

Se determinó el contenido de proteína presente en las hojas después del proceso de extracción de proteína, con el fin de determinar la cantidad de proteína extraída y calcular el rendimiento de extracción, como se muestra en la Tabla 6. Allí, se observa que el mayor rendimiento se logró en la extracción de proteína de jatropha, y cuyo valor se asemeja a los resultados establecidos por otros autores para la extracción proteica de leguminosas (45\%) [53]. Por otro lado, los rendimientos obtenidos para las otras 3 muestras, se encuentran muy por debajo de las logradas durante la extracción de proteínas como la de pasto elefante $(11,68 \%)$ [31], leguminosas Cubanas (10-12\%) [54] y maíz (19.38\%) [45], mostrando la necesidad de evaluar nuevas metodologías que permitan aumentar estos valores. 
Tabla 6. Contendido de proteína en las hojas después de la extracción y rendimiento de extracción

Table 6. Leaves protein content after the extraction process and extraction yields

\begin{tabular}{|l|c|c|}
\hline Muestra & $\begin{array}{c}\text { Proteína en hojas } \\
\text { después de la } \\
\text { extracción (\%) }\end{array}$ & $\begin{array}{c}\text { Rendimiento de } \\
\text { extracción (\%) }\end{array}$ \\
\hline PY-T & 16.98 & 2,58 \\
\hline PY-V & 15.34 & 3,58 \\
\hline PJ & 12.59 & 31,24 \\
\hline PG & 6.34 & 4,95 \\
\hline
\end{tabular}

El proceso de extracción de proteínas a partir de fuentes vegetales, está limitada por la capacidad para generar el rompimiento de las células vegetales, que comparadas con los tejidos animales y las células bacterianas, presentan menor contenido de proteínas y contienen en sus vacuolas enzimas, alcaloides y compuestos fenólicos que pueden intervenir con la actividad proteica [55], de allí la variación que se presentó para los porcentajes de extracción, ya que cada fuente foliar presenta ciertas características diferentes en su composición.

En cuanto a los rendimientos de precipitación, en las Figuras 3 y 4 se muestran los resultados obtenidos para la precipitación a temperatura ambiente y a $50{ }^{\circ} \mathrm{C}$ respectivamente, donde se observa que el incremento en la temperatura se tradujo de manera general en un aumento del rendimiento de precipitación.

Figura 3. Rendimientos de precipitación de proteína a temperatura ambiente

Figure 3. Proteín precipitation yields at room temperature

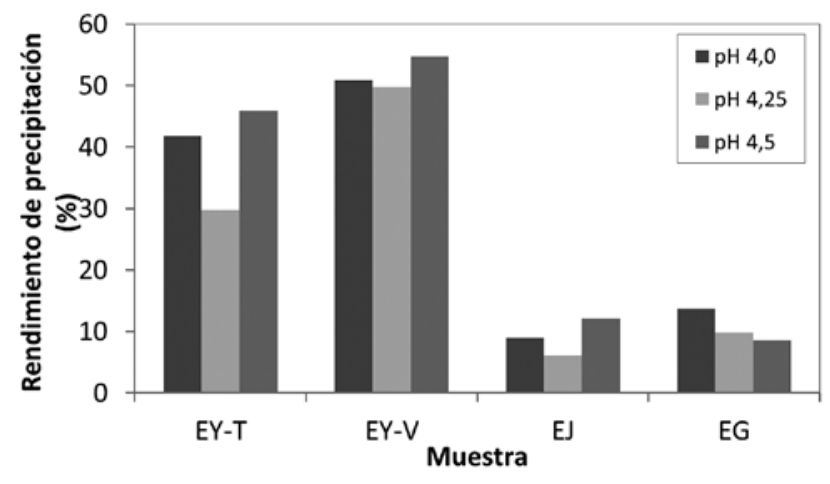

Teniendo en cuenta que los mayores contenidos de proteína y que los mejores rendimientos de precipitación se alcanzaron cuando ésta se realizó a $50^{\circ} \mathrm{C}$, se establece que esta condición de temperatura, corresponde al mejor valor para realizar la precipitación de proteínas foliares, de allí que la máxima precipitación alcanzada se presentó con la muestra de yuca variedad verónica $(75,89 \%)$. No obstante, la muestra de jatropha a pesar de presentar los mayores rendimientos de extracción, obtuvo los menores de precipitación para ambos tratamientos, entre 8,97\% y 12,13\% para temperatura ambiente y $8,78 \%$ y $16,40 \%$ para la precipitación a $50{ }^{\circ} \mathrm{C}$, lo anterior es debido a la poca cantidad de precipitado obtenido, mas no al contenido de proteína presente en el mismo, situación similar al comportamiento de las hojas de gmelina, que alcanzaron rendimientos de precipitación entre $15,55 \%$ y $22,04 \%$, encontrándose ambas por debajo de los valores alcanzados para la precipitación de proteínas de pasto elefante (38,37\%-62,51\%) [31].

Figura 4. Rendimientos de precipitación a $50^{\circ} \mathrm{C}$

Figure 4. Precipitation yields at $50^{\circ} \mathrm{C}$

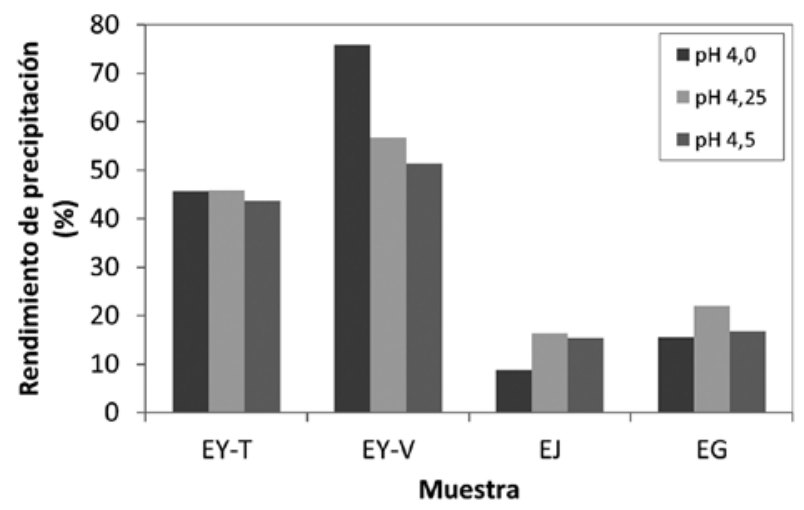

A pesar de que el rendimiento de precipitación de proteína a partir de las hojas de jatropha fue el menor, ésta fuente foliar permitió obtener el precipitado con el mayor contenido de proteína comparado con las otras 3 muestras aquí estudiadas. Sin embargo, se debe tener en cuenta que el proceso llevado a cabo no solo permitió la precipitación de proteínas sino también de otras sustancias desconocidas que afectaron la pureza del extracto proteico.

\section{CONCLUSIONES}

La extracción de proteína a partir de fuentes foliares surge como una alternativa para el aprovechamiento de residuos generados en actividades agroindustriales, lo cual se puede traducir en una reducción del impacto ambiental. No obstante, es necesario establecer mejores procesos para la precipitación de proteína, que permitan obtener extractos con mayores porcentajes de proteína, teniendo en cuenta que el incremento en la temperatura de precipitación permite la obtención de precipitados con mayor contenido proteico. En cuanto a las fuentes foliares estudiadas en la presente investigación, las proteínas presentes en la de hoja de jatropha (jatropha curcas L.) presentan su punto isoeléctrico a un valor de $\mathrm{pH}$ de 4,5 , y las de yuca (Manihot esculenta Crantz) variedad tai a $\mathrm{pH} 4,0$, mientras que para la gmelina y la yuca variedad verónica no existió 
diferencia estadísticamente significativa entre los contenidos de proteína obtenidos en los valores de $\mathrm{pH}$ evaluados. De las cuatro fuentes foliares evaluadas, la jatropha (jatropha curcas L.), presentó el mayor contenido de proteína en el precipitado y el mejor rendimiento de extracción, sin embargo esta muestra exhibió el menor rendimiento de precipitación.

\section{AGRADECIMIENTOS}

Los autores agradecen al Departamento Administrativo de Ciencia, Tecnología e Innovación por el programa de Jóvenes Investigadores e Innovadores, cuyo apoyo fue esencial para la realización de este trabajo.

\section{REFERENCIAS}

[1] Ministerio de Agricultura y desarrollo rural (2006) $\mathrm{Ob}$ servatorio Agrocadenas Anuario 2005 Agroindustia y competitividad [Internet], Bogota, Mundo 3D. Disponible desde: $<\mathrm{http}$ ://www.google.com.co/url?sa=t\&rct=j\&q=\&esrc=s\&s ource $=$ web\&cd $=1 \&$ cad $=$ rja\&ved $=0 C C k Q F j A A \& u r l=h t t p \%$ 3A\%2F\%2F190.60.31.203\%3A8080\%2Fjspui\%2Fbitstream \%2F123456789\%2F3044\%2F1\%2F179.pdf\&ei=dWTqUrW XCtOHkQfUrYGIBA\&usg=AFQjCNGKHfmuZk5Te2BQ 85q7IRQFh8cddQ\&bvm=bv.60444564,d.eW0> [Acceso 10 junio 2013]

[2] Ceballos, H., Morante, N., Calle, F., Lenis, J. I., Jaramillo, G., and Pérez, J. C. (2002) Mejoramiento genetic de la yuca. En: Ospina, B., ed.; Ceballos, H., ed. La yuca en el tercer milenio: sistemas modernos de producción, procesamiento, utilización y comercialización CIAT; Clayuca, Cali, p. 295-326.

[3] Alzate, A.M., Vallejo Cabrera, F.A., Ceballos Lascano, H., Pérez, J.C., and Fregene, M., Variabilidad genétic de la yuca cultivada por pequeños agricultores de la región Caribe de Colombia, Acta Agron., 59 (4), 385-393, 2010.

[4] Gottret, M.V., Escobar, Z., and Pérez, S. (2002). El sector yuquero en Colombia. En: Ospina, B., ed.; Ceballos, H., ed. La yuca en el tercer milenio: Sistemas modernos de producción, procesamiento, utilización y comercialización. CIAT; Clayuca, Cali, p. 340-376.

[5] Food and Agriculture Organization of the United Nations. (Octubre 2013). FAOSTAT [Internet], Food and Agriculture Organization of the United Nations. Disponible desde: <http://faostat.fao.org/site/339/default.aspx> [Acceso 10 noviembre 2013].

[6] Giraldo, A., Velasco, R.J., and Villada, H.S, Digestibilidad aparente de una harina proveniente de hojas de yuca (Manihot esculenta crantz), Inf tecnol., 19 (1), 11-18, 2008.
[7] Buitrago, J., and Lucket, Ll. (1997) Potencial de la yuca industrial para produccion de alimentos balanceados para animales. En: IICA, ed. Primer ecuentro técnico Nacional de Produccion y Transformación de yuca. Tolu, IICA, 143-149.

[8] Quiroga, P.N., and Olmos, V., Revisión de la toxicocinética y la toxicodinamica del ácido cianhidrico y los cianuros, Acta Toxicol. Argent., 20-32, 2009.

[9] Guerreo Pinilla, J.A., Campuzano, L.F., Rojas, S., and Pachon-García, J., Caraterización morfológica y agronómica de la colección nacional de germoplasma de Jatropha curcas L. Orinoquia, Redalyc, 15(2), 131-147, 2011.

[10] Toral, O. C., Iglesias, J. M., Montes de Oca, S., Sotolongo, J. A., García, S., and Torsti, M., Jatropha curcas L., una especie arbórea con potencial energético en Cuba. Pastos y Forrajes, 191-207, 2008.

[11] Johanes, H., and Hirata, S., Biodisel production from crude Jatropha curcas L. seed oil with a high content of free fatty acids, Biores. Tech., 1716-1721, 2007.

[12] Pedraza Sánchez, E. A., and Cayón Salinas, D. G., Caracterización morfofisiológica de Jatropha curcas L. variedad Brasil cultivada en dos zonas de Colombia, Acta Agron., 30-36, 2010.

[13] Agroforestal de Colombia. (2008) Adaptación del piñón Jatropha curcas L. [Internet], Puerto Carreño, Agroforestal de Colombia. Disponible desde: <http://www.corpoica. org.co/sitioweb/Documento/JatrophaContrataciones/JORGEBENDECK2.pdf> [Acceso 1 de julio 2013]

[14] Camino al Agro. (2011) Cultivo de jatropha I. [Internet], Santafé de Antioquia, Camino al agro. Disponible desde: $<$ http://www.youtube.com/watch?v=Br-QqTTMwLA> [Acceso 27 de junio 2013]

[15] Chaudhary, D., Ghosh, A., Chikara, J., and Patolia, J., Soil characteristics and mineral nutrient in wild Jaropha population of India, Commun Soli Sci Plan., 39, 1476-1485, 2008.

[16] Makkar, H., Maes, J., and Greyt, W., Removal and degradation of phorbol esters during pre-treatment and transesterification of (Jatropha curcas L.) oil, JAOCS, 173-181, 2009.

[17] IDEAM. (2009) Informe anual sobre el estado del medio ambiente y los recursos naturales renovables en Colombia Bosques 2009 [Internet], Bogota, IDEAM. Disponible desde: $<$ https://documentacion.ideam.gov.co/openbiblio/Bvirtual/021721/PAG_97-116.pdf> [Acceso 1de julio de 2013].

[18] Tiwari, N., Yadav, A.K., Srivastava, P., Shanker, K., Vema, R.K., and Gupta, M.M., Iridpoid glycosides from Gmelina arborea, Phytochem., 2387-2390, 2008. 
[19] Obregón, C., Gmelina arborea: Versatilidad, renovación y productividad sostenible para el futuro. Revista M\&M, 50, 14-20, 2006.

[20] Barrios, A., López, A. M., Nieto, V., Burgos, N., Yaya, M., \& González, I., Efecto del control de malezas y fertilización sobre el crecimiento inicial de una plantación de Gmalina arborea Roxb. en el deparatamento del Tolima, Colombia, Colombia Forestal, 14(1), 31-40, 2011.

[21] Sosa Rubio, E. E., Pérez Rodríguez, D., Ortega Reyes, L., and Zapata Buenfil, G., Evaluación del potencial forrajero de árboles y arbustos tropicales para la alimentación de ovinos, Rev. Téc. Pec. Mex., 129-144, 2004.

[22] Murgueitio, R., Sistemas agroforestales para la produccion ganadera en Colombia, Pastos y Forrajes, 1-11, 2000.

[23] Chanchan, W., and Jianping, W., Preparation and characterization of adhesive from spent hen proteins, Int J Adhes Adhes., 36, 8-14, 2012.

[24] Trompiz, J., Gómez, Á., Rincón, H., Ventura, M., Bohórquez, N., and García, A., La harina de yuca en el rngorde de cerdos. Agronom.Trop., 143-149, 2007.

[25] Lianqing, S., Xiangyang, W., Zhongyng, W., Yuanfeng, W., and Jianshe, C., Studies on tea protein extraction using alkaline and anzyme methods, Food Chem., 107(2), 929938, 2008.

[26] Martínez Maqueda, D., Hernández Ledesma, B., Amigo, L., Miralles, B., \& Gómez Ruiz, J. Á. (2013) Extraction/ Fractionation techniques for proteins and peptides and protein digestion. En: Toldrá, F., ed.; Nollet, L.M, ed. Proteomics in foods. New York, Springer, p. 21-51.

[27] Nelson, D., and Cox, M., Lehniger Principles of biochemestry. Estados Unidos: Worth Publishers, 2000.

[28] Perry, H., Green, D., and Maloney, J., Manual del ingeniero químico. Madrid: McGraw Hill Interamericana, 2001.

[29] Guo, R., Pang, S., and Wang, K., Studies of the alkali and enzyme methods for rice protein extraction and the comparision of their functionalities, Ship. Kex., 26, 173-177, 2005

[30] Sun, Q., and Tian, Z., Studies of rice protein extraction using an alkali method, Shiping Gongye Keji, 24, 38-40, 2003.

[31] Urribarrí C.,L., Ferrer O.A., and Colina, A., Extraccion y proteina de las proteinas solubles del pasto elefante enano (Pennisetum purpureum Scum cv. Mott). Revista Fac. Agron., 268-279, 2004.
[32] Spell, L., and Bressani, R., Preparación y caracterización química y nutricional de la proteína foliar de la chaya (cnidoscolus aconitifolius). Revista UVG, 54-60, 2011.

[33] Oboh, F.O., and Masodje, H.I., Nutritional and antimicrobial properties of Jatropha tanjorensis leaves, AEJS Reasearch, 4(1), 7-10, 2009.

[34] Castellanos, R., Altamirano, S., and Moretti, R., Nutritional characteristics of cassava (Manihot esculenta Crantz) leaf protein concentrates obtained by ultrafiltration and acidic thermocoagulation, Plant Food Hum Nutr., 45 (4), 357-363, 1994

[35] Duke, J. A. Handbook of energy crops (unpblished). Purdue University, Center for New Crops \& Plants Products, West Lafayette, Indiana, 1987.

[36] Karabulut, A., Canbolat, O., Ozcan, C. O., and Kamalak, A., Potential nutritive value of some mediterranean shrub and tree leaves as emergency food for sheep in winter. LRRD, 18(6), 1-5, 2006.

[37] Lestary, D. (2012) Non-food applications of jatropha proteins. Tesis de Doctorado,Wageningen University, 2012.

[38] Macías de Costa, S., Montenegro, M. A., Arregui, T., Sánchez de Pinto, M. I., Nazareno, M. A., and López de Mishima, B., Caracterizacion de acelga fresca de Santiago del Estero (Argentina). Comparación del contenido de nutrientes en hoja y tallo. Evaluación de los carotenoides presentes. Ciênc. Tecnol. Aliment. , 23(1), 33-37, 2003.

[39] Veloz Herrera, M. C. (2004) Evaluación de dos métodos de henificación de pastos. Tesis de Doctorado, Universidad Central del Ecuador, 2004.

[40] Kartira, I. A., Yuliani, S., Kailaru, S., and Rigal, L., Moisture sorption behaviour of jatropha seed (Jatropha curcas) as a source of vegetable oil for biodisel production, Biomass Bioenergy, 36, 226-233, 2012.

[41] García, D.E., Medina, M.G., Perdomo, D.A., Moratinos, P., Cova, L., and Clavero, T., Efecto de algunos factores que influyen en el rendimiento de proteina bruta de la morera (Morus alba L.) en el estado de trujillo, Venezuela. Zootecnia Trop., 29 (4), 411-420, 2011.

[42] Pedraza Olivera, R. M., Martínez Sáez, S. J., Estévez Alfayate, J. A., Guevara Viera, G. F., Guevara Viera, R. E., \& Curbelo Rodríguez, L., Valor nutritivo para rumiantes del follaje de árboles y arbustos tropicales. Rev. Prod.Anim., 5-12, 2007

[43] Sierra Posada, J. Ó., Funadamentos para el establecimiento depasturas y cultivos forrajeros. Editorial Universidad de Antioquia, Medellin, 2005. 
[44] Lyons, R. K., Manchen, R., and Forbes, T. D., ¿Por que cambia la calidad del forraje de los pastizales? AgriLife Ext., 1-8, 1999.

[45] Molina Navas, V.A. (2005). Extracción de proteína foliar de maíz a los 10, 25 y 40 días de la siembra y análisis de sus aminoácidos. Tesis para optar al título de Ingeniera Agroindustrial en el grado Académico de Licenciatura, Zamorano, 2005.

[46] Rincón, Á., Evaluación agronómica de variedades de caña de azucar con potencial forrajero en el Piedemonte Llanero, Corpoica, 2-16, 2005.

[47] Rothstein, F. (1994). Differential precipitation of proteins. En: Harrison, R., ed. Protein purification process engineering. New York, R.G. Harrison, p. 115-208.

[48] Messerschmidt, A., \& Huber, R. (2007). X-Ray Driffraction of Biological Macromolecules. En R. A. Meyers, Proteins from Analytics to Structural Genomics (págs. 3-80). 1ARKSPUR: Wiley- VCH.

[49] Carraco, M.E., Castillo, R.M., Escamilla, A., Martínez, M., Pérez Gil, F., and Stephan, E., Composición química, extracción de proteina foliar y perfil de aminoacidos de siete plantas acuaticas, Rev. Cubana Cienc. Agríc., 36 (3), 247-258, 2002
[50] Segal Kischinevzky, C. A., and Ortega Lule, G. J., Manual de prácticas Biologia Molecular de la célula I., Facultad de Ciencias de la UNAM, Mexico, 2005.

[51] Soto, E., Miranda, R. d., Sosa, C. A., and Loredo, J. A., Optimización del proceso de remoción de metales pesados de agua residual de la industria galvánica por precipitación química, Inf tecnol., 17 (2), 33-42, 2008.

[52] Manahan, S. E., Introducción a la química ambiental.Editorial Reverté S.A, Mexico D.F., (2007).

[53] Sentheshanmuganathan, S., and Durand, S., Isolation and composition of protein from leaves of plants grown in $\mathrm{Ce}-$ ylon, J. Sci.Food Agric., 20, 603-608, 1969.

[54] Díaz, M., Gonzáles, A., Curbelo, F., Cruz, A., \& Mora, C., Evaluacion de leguminosas de alto valor proteico en la obtencion de concentrados de proteína foliar (CPF). Rev. Cubana Cienc. Agric., 31, 183-188, 1997

[55] Llorente, B.E. (2000) Aislamiento, Purificación, Caracterización y producción in vitro de peptidasas de alcaucil coagulantes de la leche. Tesis de Doctorado,Universidad Nacional de la Plata, 2000. 